\title{
ASSESSMENT OF STOCK LENGTH FOR ONE DIMENSIONAL CUTTING STOCK PROBLEM (1D-CSP) WITH SUSTAINABLE TRIM LOSS
}

\author{
VIRESH SHARMA ${ }^{1} \&$ SIBY SAMUEL ${ }^{2}$ \\ ${ }^{I}$ Department of Mathematics, NAS PG College, Meerut, India \\ Department of Computer Science, St. Aloysius College, Jabalpur, Madhya Pradesh, India
}

\begin{abstract}
The cutting stock problem is cutting of orders of a certain number of small pieces from available large pieces in stock in such a way that trim loss is minimized. The main objective of this problem is to minimize the scrap which is called trim loss. There are various methods which were studied earlier focusing on the minimization problem of the waste.In the present paper, we have designed the algorithm which predicts the length of the stock with the basic aim to minimize the trim. The stock length has been determined with the constraint of lower and upper bounds with respect to the length which is desirable in view of the demand and the transportation respectively.

Initially, we have introduced the variable $t$ as the percentage of the pre-defined sustainable trim. By fixing $t$, the value of the stock-length and its corresponding actual trim loss has been calculated for different combinations of the order lengths. It has been observed that the variable t plays a key role in deciding the number of various stock lengths of different measures and to control the total trim loss.
\end{abstract}

KEYWORDS: Cutting Stock Problem, Sustainable Trim Loss, Assessment of Stock Length

Received: Jun 01, 2020; Accepted: Jun 20, 2020; Published: Jul 02, 2020; Paper Id.: IJMPERDJUN2020171

\section{INTRODUCTION}

A cutting stock problem (CSP) is a problem that includes cutting of large pieces available in stock to produce smaller pieces (called items) in order to meet a given demand. In case of One Dimensional, the cutting is planned to minimize the waste of stock length used and maximize profit. The main objective of the cutting plan is to obtain the required number of small pieces from the available stock lengths with minimum trim loss. Many methods have been derived either with exact or heuristic approaches for solving the 1D-CSP. These approaches are used for generating cutting patterns by considering combinations of order length that can be cut from a given stock length.

Now, the focus of research has been shifted to apply multiple criteria approaches to optimize CSP. In 2008 Rodriguez \& Vecchietti [11] introduced a method where the cutting stock algorithms were linked with decisionsupport tools, the input to the algorithm being selected by criteria defined by a decision-support tool enabling better business performance and Dikili et al.[3] developed a new heuristic approach to 1D-CSP with multiple stock lengths which broadens the view for the solution compared to the use of single sized stock material.

The purpose of this paper is to develop a mathematical model to assess the stock length for solving 1DCSP for Transmission tower manufacturing industry. The determination of the stock length is acceptable when the expected trim loss is minimum, transportation is feasible and warehousing is manageable. The main objectives of all researchers working in this direction are to minimize the waste and maximize the profit. Thus, there is need for 
an easy approach to operate and interpret cutting stock problem for improving operational efficiency. Therefore, this model will determine the stock length and produce the cutting patterns which will result in minimizing the trim loss.

This paper is organized as follows: Section 2 explains Problem definition and mathematical formulation. Algorithm is given in section 3. Section 4 covers the illustrative example to demonstrate practical application of the model. Section 5 presents the comparative study with the model developed by Power et al [10]. Section 6 presents the concepts and illustrations of minimization of number of stock lengths assessed. Finally, the last section 7 concludes the proposed study.

\section{Problem Definition and Mathematical Formulation}

In one-dimensional cutting stock problem, different lengths of available stock play a crucial role in determining the trim loss. The main objective of the paper is to assess stock length in such a way that the further minimization of the trim loss may be claimed in comparison to the earlier methods dealing with 1DCSP in which the prescribed stock lengths have been considered. Our study is totally focused on Transmission tower manufacturing Industry. It may be noted that the length of stock depends on the following issues:

- Due to the limitations on the modes of transportation, the upper bound of the length of the stock cannot exceed 14 meters.

- The minimum size of the stock length has been fixed as 7 meters as the production of stock length less than this measure $(7 \mathrm{~m})$ is not feasible (financially) for the supplier.

Considering the working space constraint of the Industry and to reduce the manpower at working space for sorting, we have proposed cutting of at most two types of order lengths in each step of cutting. In view of aforesaid, we have therefore imposed the upper (14 meters) and the lower ( 7 meters) bound of the stock to be determined.

We are now set to define our problem exclusively as follows:

Given: $l_{1}, l_{2}, \ldots, l_{n}$ the order lengths (arranged in descending order with respect to length) with the corresponding required number of pieces $d_{1}, d_{2}, \ldots, d_{n}$ respectively.

Let, $u(=7 \mathrm{mts})$ be the lower bound and $U(=14 \mathrm{mts})$ be the upper bound of the stock length respectively. Also $U_{j}(j=1,2, \ldots, k)$ denote the stock lengths to be determined where $\mathrm{k}$ depends on the cutting process for a particular dataset.

$t_{j}$ trim loss corresponding to the stock length $U_{j}$.

$C_{j}$ a real number which is to be determined in terms of sustainable trim loss, pre-defined by the industry.

$U_{i j}$ combinations of order lengths $l_{i}$ and $l_{j}$ such that $u \leq U_{i j} \leq U$

$p_{i j}$ number of order length $l_{i}$ being cut from the stock length $U_{j}$

Keeping in view the practical approach of cutting in Tower Industries, we design the mathematical model as follows:

Objective: To determine the stock length $U_{j}$, satisfying the condition $u \leq U_{j} \leq U$ such that the trim loss should be minimum, we define the model of CSP as:

$\min \sum_{j=1}^{k} t_{j}$ (minimization of trim loss)

$$
t_{j} \geq 0 \forall j
$$


subject to the condition

$U_{j}=\max _{j}\left\{U_{i j}: U_{i j}=\alpha l_{i}+\beta l_{j}\right.$ and $u \leq U_{i j} \leq U, i=1, j=2, \ldots, n ; i<j ; \alpha, \beta$ are positive integers $\}$

Note: $i$ is assumed to be 1 , because the order length $l_{1}$ being the largest among all order length is considered to be cut at the initial stages.

$\sum_{j=1}^{k} p_{i j}=d_{i} \quad$ (demand constraint)

Where, $p_{i j}=\left\{\begin{array}{c}=0, \text { if the order length } l_{i} \text { is not cut } \\ \quad \text { from the stock length } U_{j} \\ >0(\text { integer }), \text { if the order length } l_{i} \text { is } \\ \text { cut from the stock length } U_{j}\end{array}\right.$

$t_{j}=\left(U_{j}-\left(\alpha l_{i}+\beta l_{j}\right)\right) \leq C_{j}$

Where, $C_{j}=\frac{t * U_{j}}{100}$

( $t \%$ trim loss may be permissible for the

stock length $\left.U_{j}\right)$

Initially, the combinations are made by combining the first order length say $l_{1}$ with rest of the order lengths i.e., $l_{j}$ where $j=2,3, \ldots n$. The first order length $l_{1}$ (being the largest in the order list) is considered to be cut at the first stage of the cutting process as the smaller lengths can be adjusted easily later.

Define: $U_{1 j}=\alpha l_{1}+\beta l_{j}$ for $1 \neq j ; \alpha, \beta$ are non-negative integers; $j=2,3 \ldots, n$

Now select the combination of the order lengths with the maximum value which lies between $u$ and $U$.

i.e., $\$=\left\{U_{1 j}: u \leq U_{1 j} \leq U\right\}$ for $1 \neq j ; j=2,3, \ldots, n$

Now define,

$U_{1}=\max _{U_{1 j} \in \Phi} U_{1 j}(j=2,3, \ldots, n)$

$U_{1}$ has been determined as the first stock length; it is used to cut as many combinations as possible of the order lengths, as long as the trim loss after cutting is sustainable to the industry.

\section{Computation of the Constant $\mathrm{C}_{1}$}

Referring (5) a constant is computed depending on the pre-defined sustainability of the industry. In order to have smooth and profitable running, the industry can sustain the trim loss (t \%) that ranges from $1 \%$ to $3 \%$.

Therefore, for first stock length $U_{1}$ the constant $C_{1}$ is calculated as

$C_{1}=\frac{U_{1} * t}{100}$

such that, $\min \left(U_{1}-U_{1 j}\right) \leq C_{1}$ for some values of $j$

The stock length $U_{1}$ determined is used to cut the combination $U_{1 j}$, at this point the trim loss will be zero since $U_{1}=$ $U_{1 j}$ 
Now, consider the required number of pieces to be cut, ie. $d_{1}$ and $d_{j}$ of the corresponding order lengths $l_{1}$ and $l_{j}$ respectively, used for the combination of $U_{1 j}$. Various cases are to be considered for further processing:

Case I: $d_{1}=d_{j}$, the cutting of both the order lengths $l_{1}$ and $l_{j}$ for fixed $j$, is completed.

Case II: $d_{1}<d_{j}$, the cutting process of $l_{1}$ is completed and for $l_{j}$ order length, $d_{j}-d_{1}$ required number of pieces are left to cut.

Case III: $d_{1}>d_{j}$, the cutting process of $l_{j}$ is completed and for $l_{1}$ order length, $d_{1}-d_{j}$ required number of pieces are left for cutting.

These three cases may arise for all values of $j$ for which (8) holds.

Considering the case I, we shall arrange the remaining $(n-2)$ order lengths in descending order with respect to length and proceed as above up to the cutting of next two order lengths. The new combination $U_{1 k}$ obtained

$$
U_{1 k}=\alpha l_{1}+\beta l_{k} ; k \neq j
$$

such that $\left\{U_{1 K}: u \leq U_{(1 k)} \leq U\right\}$. The obtained $U_{1 k}$ is checked with $U_{1}$ [cf.(6)] such that

$\min \left(U_{1}-U_{1 k}\right) \leq C_{1}$ for some values of $k$; (9)

for $C_{1}$ refer (7).

If (9) satisfies then it undertakes the cutting process from stock length $U_{1}$ [cf. (6)]. During this cutting process, we may again come across the three cases and continue till the order length $l_{1}$ is cut entirely.

If (9) does not satisfy, we define

$$
U_{2}=\max _{k} U_{1 k}
$$

for $1 \neq k ; k=2,3, \ldots, n ; k \neq j$.

$U_{2}$ is considered as the second new stock length and the corresponding sustainable trim $C_{2}$ has been computed as $C_{1}$ (refer (5)). Hence,

$C_{2}=\frac{U_{2} * t}{100}$ which is pre-defined sustainable trim loss.

Subject to case II, we know that $d_{j}-d_{1}$ number of pieces of order $l_{j}$ is remaining in the cutting procedure. The remaining $(n-1)$ order lengths are again rearranged in the descending order with reference to the length viz. $l_{1}, l_{2}, \ldots, l_{n-1}$ with required number of pieces $d_{1}, d_{2}, \ldots, d_{n-1}$ respectively. Following the same technique described above, we obtain the combinations of the order length say $U_{1 k}$ and check the conditions [cf. (2), (9)]. If (9) satisfies, then this combination can be cut using $U_{1}$ or else we determine the obtained $U_{1 k}$ as $U_{2}$ the second new stock length and then we again come across with three cases and the process is continued to cut the required pieces of order lengths.

In view of case III, we know that the cutting process of order length $l_{1}$ is not completed, it is left with $d_{1}-d_{j}$ number of pieces to be cut, so again the combinations are obtained after arranging the left order lengths in descending, if 
the combination $U_{1 k}$ obtained satisfy the condition (2) and (9) then it is cut using stock length $U_{1}$ else $U_{1 k}$ is considered as the second new stock length $U_{2}$ and the corresponding sustainable trim $C_{2}$ is been computed.

This process continues till all the required pieces of the order lengths are exhausted.

Note: The new stock length determined should be tested with the previously assessed stock length, to check whether the new stock length can be used for any previously determined stock length which lies within the sustainable trim loss.

At the end of the cutting process we may come across two cases viz.,

- $U_{1 m}<u$, then we have to consider the lower bound of the stock length $u=7 \mathrm{mtrs}$, since the stock length less than 7 mtrs is not feasible by the supplier to supply.

- There is always a possibility that only one order length is left to cut. In this case, the order lengths will be cut using already determined stock lengths in multiple pieces, if required.

\section{ALGORITHM}

- Read the order length $l_{i}$ and demand $d_{i}$, and arrange them in descending order.

- function caller A for criteria II (to find the larger sized order length preset to $35 \%$ to $40 \%$ ) go to line number 33

- do while $(n>0)$

- for $i=1$ to $n-1$

- for $j=2$ to rit?

- calculate $U_{i j} \quad \alpha l_{1}+\beta l_{j} ; \alpha, \beta$ are positive integers

- goto 4 for $j \leq n$

- $\quad$ goto 3 for $i \leq n-1$

- $U_{i j}=\max _{j}\left(U_{i j}: u \leq U_{i j} \leq U\right)$

- $\quad U_{j}=U_{i j}$ (assessment of Ist order length $U_{j}$ and then subsequent); for $j=1,2, \ldots, n$

- $\quad$ calculate $C_{j}=\frac{t * U_{i j}}{100} ; t=2$

- $\quad$ if $t_{j}=\min \left(U_{j}-U_{i j} \leq C_{j}\right)$

- Note: Proceed for cutting plan;

- check $l_{i}$ in array // checking using function call A for Criteria II

- if found store $U_{j}$ in an array $1 ; j=1,2 \ldots / /$ store stock length used to cut larger sized order length-Criteria II

- $w_{j}++; i \phi U_{j}$ is used to cut a combination, increment $w_{j}, j=1,2 \ldots, n /$ /used for Criteria I

- calculate $t_{j}=U_{j}-U_{i j}$

- $\quad$ if $d_{1}=d_{j}$

- remove $l_{i}, l_{j}$ and $d_{i}, d_{j}$ from the order list.

- $n=n-2$

- $\quad$ if $d_{1}<d_{j}$

- $\quad$ remove $l_{1}$ and $d_{1}$ and update $d_{j}=d_{j}-d_{1}$ 
- $n--$

- $\quad$ if $d_{1} \geq d_{j}$

- $\quad$ remove $l_{j}$ and $d_{j}$ and update $d_{1}=d_{1}-d_{j}$

- $n--$

- $\quad$ else

- $U_{j}=U_{i j} ; j=2,3, \ldots$ : repeat for $U_{3}, U_{4}, \ldots$ if $t_{j}=\min \left(U_{j}-U_{i j} \geq C_{j}\right)$

- $\quad$ if $U_{i j} \leq u$

- $U_{j}=700$

- $\quad$ calculate $g t_{j}=g t_{j}+t_{j}$

- $\quad$ go to line no 3 till $l_{i}=0, d_{i}=0$

- $\quad$ print $U_{j}, g t_{j}$

- Function callee $A$

- $\quad$ large $=$ calculate $40 \%$ of $\mathrm{n}$ (total number of order lengths)

- for $i=1$ to large

- $\quad$ push $l_{i}$ in array for $i \leq$ large; go to line 3

Note: Minimization of stock length assessed

\section{Criteria I}

- $\quad$ select $U_{j}$ for $w_{j} \geq 2$

- continue cutting plan with selected stock lengths $U_{j}$

\section{Criteria II}

- continue cutting plan using stock length store in arrayl

\section{Criteria III}

- calculate $40 \%$ of total stock $T U_{j}$

- $\quad$ select stock length $U_{j} \geq T U_{j}$; store it in array2 and continue the cutting plan

Note: Function for cutting plan after minimization of stock length assessed

- do while $(n>0)$

- $\quad$ for $i=1$ to $n-1$

- for $j=2$ to $n$

- $\quad$ calculate $U_{i j}=\alpha l_{1}+\beta l_{j} ; \alpha, \beta$ are positive integer

- $\quad$ goto 3 for $j \leq n$

- $\quad$ goto 2 for $i \leq n-1$

- $U_{i j}=\max _{\mathrm{j}}\left(U_{i j}: u \leq U_{i j} \leq U\right)$

- $\quad$ for $i=1$ to len(array2) 
- if array $2[i] \geq U_{i j}$

then if found proceed for cutting process

else go to line 8 for next $\mathrm{i}$

- calculate $t_{j}=U_{j}-U_{i j}$

- $\quad$ if $d_{1}=d_{j}$

- remove $l_{i}, l_{j}$ and $d_{i}, d_{j}$ from the order list.

- $n=n-2$

- if $d_{1}<d_{j}$

- $\quad$ remove $l_{1}$ and $d_{1}$ and update $d_{j}=d_{j}-d_{1}$

- $n-$

- if $d_{1} \geq d_{j}$

- $\quad$ remove $l_{j}$ and $d_{j}$ and update $d_{1}=d_{1}-d_{j}$

- $n-$

- else

- $U_{j}=U_{i j} ; j=2,3, \ldots$ : repeat for $U_{3}, U_{4}, \ldots$ if $t_{j}=\min \left(U_{j}-U_{i j} \geq C_{j}\right)$

- $\quad$ if $U_{i j} \leq u$

- $U_{j}=700$

- calculate $g t_{j}=g t_{j}+t_{j}$

- $\quad$ go to line no 1 till $l_{i}=0, d_{i}=0$

- $\quad \operatorname{print} U_{j}, g t_{j}$

\section{COMPARATIVE STUDY}

A comparative study of this proposed model was done with the model on first order sustainable trim developed by Powaret al.(2013). They have determined the sustainable trim loss $t_{s}^{1}$, based on which the cutting patterns are generated whereas this model deals with calculating a constant based onbearable trim loss sustained by the industry which ranges from $1 \%$ to $3 \%$. They have considered the model in two categories with cutting two order lengths at a time; Category I- when the required numbers of pieces of order lengths are integral multiples of each other and Category II- when the required numbers of pieces of order lengths are prime numbers. In both the categories they have determined the cutting of order lengths two at a time in order to satisfy the requirement of minimum work area, less manpower and in particular the acceptable trim within the range of the industry whereas this model also considers cutting of two order lengths at a time with $\alpha$ and $\beta$ times, where $\alpha, \beta=$ $1,2, \ldots, n$. The comparison was done on the number of stock lengths used, trim loss per stock length, total stock length used and total trim loss. 
Table 1: Cutting Plan According to Powar et al. Model

\begin{tabular}{|c|c|c|c|c|}
\hline S. No. & Order Lengths (in cm) & Pieces To Cut & Trim Loss (in cm) & Used Stock Lengths(in cms) \\
\hline \multirow{2}{*}{1} & 230 & 2 & \multirow{2}{*}{$30 \times 16=480$} & \multirow{2}{*}{$1150 \times 16=18400$} \\
\hline & 660 & 1 & & \\
\hline 2 & 750 & 1 & $0 \times 24=0$ & $750 \times 24=18000$ \\
\hline 3 & 800 & 1 & $0 \times 13=0$ & $800 \times 13=10400$ \\
\hline \multirow{2}{*}{4} & 310 & 1 & \multirow{2}{*}{$0 \times 36=0$} & \multirow{2}{*}{$1200 \times 36=43200$} \\
\hline & 890 & 1 & & \\
\hline \multirow{2}{*}{5} & 310 & 4 & \multirow{2}{*}{$10 \times 1=10$} & \multirow{2}{*}{$1250 \times 1=1250$} \\
\hline & 890 & 0 & & \\
\hline \multirow{2}{*}{6} & 400 & 1 & \multirow{2}{*}{$0 \times 39=0$} & \multirow{2}{*}{$950 \times 39=37050$} \\
\hline & 550 & 1 & & \\
\hline \multirow{2}{*}{7} & 400 & 2 & \multirow{2}{*}{$0 \times 4=0$} & \multirow{2}{*}{$800 \times 4=3200$} \\
\hline & 550 & 0 & & \\
\hline \multirow{2}{*}{8} & 460 & 1 & \multirow{2}{*}{$0 \times 21=0$} & \multirow{2}{*}{$1100 \times 21=23100$} \\
\hline & 640 & 1 & & \\
\hline \multirow{2}{*}{9} & 460 & 0 & \multirow{2}{*}{$20 \times 1=20$} & \multirow{2}{*}{$1300 \times 1=1300$} \\
\hline & 640 & 2 & & \\
\hline \multicolumn{3}{|l|}{ Total } & 510 & 155900 \\
\hline \multicolumn{4}{|c|}{ Total Trim Loss $(\%)$} & $0.33 \%$ \\
\hline
\end{tabular}

It has been observed that the model with assessment of stock length has less trim loss (.026) in comparison to the model being proposed by Powar et al $(.32 \%)$.

The cutting plan at $2 \%$ sustainable trim loss, refer Table 2.

Table 2: Cutting Plan

\begin{tabular}{|c|c|c|c|c|c|c|}
\hline S. No & $\begin{array}{c}\text { Order } \\
\text { Lengths in cm }\end{array}$ & Pieces to Cut & $\begin{array}{c}\text { Stock } \\
\text { Assessed }\end{array}$ & $\begin{array}{l}\text { No. of Stock } \\
\text { Used }\end{array}$ & $\begin{array}{l}\text { Trim Loss } \\
\text { in cms }\end{array}$ & $\begin{array}{c}\text { Used Stock } \\
\text { Length in cms }\end{array}$ \\
\hline \multirow{2}{*}{1} & 800 & 3 & \multirow{2}{*}{$U_{1}=1400$} & \multirow{2}{*}{3} & \multirow{2}{*}{0} & \multirow{2}{*}{4200} \\
\hline & 300 & 32 & & & & \\
\hline \multirow{2}{*}{2} & 740 & 24 & \multirow{2}{*}{1400} & \multirow{2}{*}{20} & \multirow{2}{*}{400} & \multirow{2}{*}{28000} \\
\hline & 320 & 40 & & & & \\
\hline \multirow{2}{*}{3} & 740 & 4 & 1400 & 4 & 80 & \multirow{2}{*}{5600} \\
\hline & 640 & 23 & & & & \\
\hline \multirow{2}{*}{4} & 730 & 46 & \multirow{2}{*}{$U_{2}=1370$} & \multirow{2}{*}{19} & \multirow{2}{*}{0} & \multirow{2}{*}{26030} \\
\hline & 640 & 19 & & & & \\
\hline \multirow{2}{*}{5} & 730 & 27 & \multirow{2}{*}{$U_{3}=1330$} & \multirow{2}{*}{13} & \multirow{2}{*}{0} & \multirow{2}{*}{17290} \\
\hline & 300 & 26 & & & & \\
\hline \multirow{2}{*}{6} & 730 & 14 & \multirow{2}{*}{$U_{4}=1270$} & \multirow{2}{*}{14} & \multirow{2}{*}{0} & \multirow{2}{*}{17780} \\
\hline & 540 & 39 & & & & \\
\hline \multirow{2}{*}{7} & 540 & 25 & \multirow{2}{*}{$U_{5}=1030$} & \multirow{2}{*}{16} & \multirow{2}{*}{0} & \multirow{2}{*}{16480} \\
\hline & 490 & 16 & & & & \\
\hline \multirow{2}{*}{8} & 540 & 9 & \multirow{2}{*}{1030} & 9 & 90 & 9270 \\
\hline & 480 & 39 & & 9 & 90 & 9210 \\
\hline 9 & 480 & 30 & $H-960$ & 21 & 0 & 10950 \\
\hline 9 & 470 & 21 & $U_{6}=$ & 21 & U & 19950 \\
\hline 10 & 480 & 9 & 960 & 4 & 0 & 3840 \\
\hline 11 & 480 & 1 & $U_{7}=700$ & 1 & 220 & 700 \\
\hline Total Tr & I Loss / Total Sto & k Used & & & 1000 & 149350 \\
\hline Trim Lo & & & & & & 0.67 \\
\hline
\end{tabular}


The number of stock length $U_{j}$ assessed for the above data set is six ie. $j=1,2, \ldots, 6$ for order lengths $l_{i}, i=$ $1,2, \ldots, 10$. At the end, one piece of order length 480 is left to cut. If it is cut using the stock lengths previously assessed then the trim loss obtained will be very high, so it can be cut using the minimum stock length $(u=7 \mathrm{mts})$.

\section{Illustration for Criterion I}

Referring table 6.2 the stock lengths satisfying criterion I are 1400, 1030, 960 therefore the cutting plan using the stock length satisfying this criterion is, please refer table 3

Table 3: Cutting Plan

\begin{tabular}{|c|c|c|c|c|c|c|}
\hline S. No & $\begin{array}{l}\text { Order Lengths } \\
\text { in } \mathrm{cm}\end{array}$ & $\begin{array}{l}\text { Pieces to } \\
\text { Cut }\end{array}$ & $\begin{array}{c}\text { Stock } \\
\text { Assessed }\end{array}$ & $\begin{array}{l}\text { No. of Stock } \\
\text { Length Used }\end{array}$ & $\begin{array}{l}\text { Trim Loss } \\
\text { in cms }\end{array}$ & $\begin{array}{c}\text { Used Stock } \\
\text { Length in } \\
\text { cms }\end{array}$ \\
\hline \multirow{2}{*}{1} & 800 & 3 & \multirow{2}{*}{1400} & \multirow{2}{*}{3} & \multirow{2}{*}{0} & \multirow{2}{*}{4200} \\
\hline & 300 & 32 & & & & \\
\hline \multirow{2}{*}{2} & 740 & 24 & \multirow{2}{*}{1400} & \multirow{2}{*}{20} & \multirow{2}{*}{400} & \multirow{2}{*}{28000} \\
\hline & 320 & 40 & & & & \\
\hline \multirow{2}{*}{3} & 740 & 4 & \multirow{2}{*}{1400} & \multirow{2}{*}{4} & \multirow{2}{*}{80} & \multirow{2}{*}{5600} \\
\hline & 640 & 23 & & & & \\
\hline \multirow{2}{*}{4} & 730 & 46 & \multirow{2}{*}{1400} & \multirow{2}{*}{19} & \multirow{2}{*}{0} & \multirow{2}{*}{26600} \\
\hline & 640 & 19 & & & & \\
\hline \multirow{2}{*}{5} & 730 & 27 & \multirow{2}{*}{1400} & \multirow{2}{*}{13} & \multirow{2}{*}{0} & \multirow{2}{*}{18200} \\
\hline & 300 & 26 & & & & \\
\hline \multirow{2}{*}{6} & 730 & 14 & \multirow{2}{*}{1400} & \multirow{2}{*}{14} & \multirow{2}{*}{0} & \multirow{2}{*}{19600} \\
\hline & 540 & 39 & & & & \\
\hline \multirow{2}{*}{7} & 540 & 25 & \multirow{2}{*}{1030} & \multirow{2}{*}{16} & \multirow{2}{*}{0} & \\
\hline & 90 & 16 & & & & 16480 \\
\hline & 540 & 9 & 1030 & 9 & 90 & 9270 \\
\hline 8 & 480 & 39 & & & & \\
\hline & 480 & 30 & 960 & 21 & 210 & 20160 \\
\hline 9 & 470 & 21 & & & & \\
\hline 10 & 480 & 9 & 960 & 4 & 0 & 3840 \\
\hline 11 & 480 & 1 & 700 & 1 & 220 & 700 \\
\hline Total & rim Loss / Stock & & & & 4300 & 152650 \\
\hline Trim & SSS \% & & & & & 2.8 \\
\hline
\end{tabular}

Illustration for Criterion II: The stock lengths satisfying the criterion II are 1400, 1370, 1330, 1270 refer table 6.2. The cutting plan using criterion II, please refer table 4.

Table 4: Cutting Plan

\begin{tabular}{|c|c|c|c|c|c|c|}
\hline $\begin{array}{c}\text { S. } \\
\text { No }\end{array}$ & $\begin{array}{c}\text { Order } \\
\text { Lengths } \\
\text { in cm }\end{array}$ & $\begin{array}{c}\text { Pieces to } \\
\text { Cut }\end{array}$ & $\begin{array}{c}\text { Stock } \\
\text { Assessed }\end{array}$ & $\begin{array}{c}\text { No. of Stock } \\
\text { Length used }\end{array}$ & $\begin{array}{c}\text { Trim } \\
\text { Loss in } \\
\text { cms }\end{array}$ & $\begin{array}{c}\text { Used } \\
\text { Stock } \\
\text { Length in } \\
\text { cms }\end{array}$ \\
\hline 1 & 800 & 3 & 1400 & 3 & 0 & 4200 \\
\hline 2 & 300 & 32 & & & & \\
\hline 3 & 740 & 24 & 1400 & 20 & 400 & 28000 \\
\hline 4 & 320 & 40 & & & & \\
\hline 5 & 740 & 4 & 1400 & 4 & 80 & 5600 \\
\hline 6 & 640 & 23 & & & & \\
\hline 7 & 730 & 46 & 1370 & 19 & 0 & 26030 \\
\hline 8 & 640 & 19 & & & & \\
\hline 9 & 730 & 27 & 1330 & 13 & 0 & 17290 \\
\hline 10 & 300 & 26 & & & & \\
\hline 11 & 730 & 14 & 1270 & 14 & 0 & 17780 \\
\hline
\end{tabular}


Table 4 Contd.,

\begin{tabular}{|c|c|c|c|c|c|c|}
\hline 12 & 540 & 39 & & & & \\
\hline 13 & 540 & 25 & 1270 & 16 & 3840 & 20320 \\
\hline 14 & 490 & 16 & & & & \\
\hline 15 & 540 & 9 & 1270 & 9 & 2250 & 11430 \\
\hline 16 & 480 & 39 & & & & \\
\hline 17 & 480 & 30 & 1270 & 21 & 6720 & 26670 \\
\hline 18 & 470 & 21 & & & & \\
\hline 19 & 480 & 9 & 1030 & 4 & 1240 & 5080 \\
\hline 20 & 480 & 1 & 700 & 1 & 220 & 700 \\
\hline
\end{tabular}

Illustration of Criterion III: The stock length satisfying the criterion III are 1400, 1370, 1030, 960, please refer table 6.2. The cutting plan using criterion III is, refer table 5 .

Table 5: Cutting Plan

\begin{tabular}{|c|c|c|c|c|c|c|}
\hline S. No & $\begin{array}{c}\text { Order } \\
\text { Lengths in } \\
\text { cm }\end{array}$ & $\begin{array}{c}\text { Pieces to } \\
\text { Cut }\end{array}$ & $\begin{array}{c}\text { Stock } \\
\text { Assessed }\end{array}$ & $\begin{array}{l}\text { No. of Stock } \\
\text { Length used }\end{array}$ & $\begin{array}{c}\text { Trim } \\
\text { Loss in } \\
\text { cms }\end{array}$ & $\begin{array}{c}\text { Used } \\
\text { Stock } \\
\text { Length in } \\
\text { cms }\end{array}$ \\
\hline \multirow{2}{*}{1} & 800 & 3 & \multirow{2}{*}{1400} & \multirow{2}{*}{3} & \multirow{2}{*}{0} & \multirow{2}{*}{4200} \\
\hline & 300 & 32 & & & & \\
\hline \multirow{2}{*}{2} & 740 & 24 & \multirow{2}{*}{1400} & \multirow{2}{*}{20} & \multirow{2}{*}{20} & \multirow{2}{*}{28000} \\
\hline & 320 & 40 & & & & \\
\hline \multirow{2}{*}{3} & 740 & 4 & \multirow{2}{*}{1400} & \multirow{2}{*}{4} & \multirow{2}{*}{20} & \multirow{2}{*}{5600} \\
\hline & 640 & 23 & & & & \\
\hline \multirow{2}{*}{4} & 730 & 46 & \multirow{2}{*}{1370} & \multirow{2}{*}{19} & \multirow{2}{*}{0} & \multirow{2}{*}{26030} \\
\hline & 640 & 19 & & & & \\
\hline \multirow{2}{*}{5} & 730 & 27 & \multirow{2}{*}{1370} & \multirow{2}{*}{13} & \multirow{2}{*}{40} & \multirow{2}{*}{17810} \\
\hline & 300 & 26 & & & & \\
\hline \multirow{2}{*}{6} & 730 & 14 & \multirow{2}{*}{1370} & \multirow{2}{*}{14} & \multirow{2}{*}{100} & \multirow{2}{*}{19180} \\
\hline & 540 & 39 & & & & \\
\hline \multirow{2}{*}{7} & 540 & 25 & \multirow{2}{*}{1030} & \multirow{2}{*}{16} & \multirow{2}{*}{0} & 16480 \\
\hline & 490 & 16 & & & & 10480 \\
\hline & 540 & 9 & 1030 & 0 & 10 & 0270 \\
\hline 8 & 480 & 39 & 1050 & 9 & 10 & 9210 \\
\hline 0 & 480 & 30 & 060 & 21 & 10 & 20160 \\
\hline 9 & 470 & 21 & 900 & 21 & 10 & 20 \\
\hline 10 & 480 & 9 & 960 & 4 & 0 & 3840 \\
\hline 11 & 480 & 1 & 700 & 1 & 220 & 700 \\
\hline Total & rim Loss / St & k Used & & & 2920 & 151270 \\
\hline Trim & oss \% & & & & & 1.9 \\
\hline
\end{tabular}

The table 3 to 5 shows the cutting plans of various criteria. Trim loss generated may vary on the data set used. Therefore, it is recommended to check the trim loss using various criteria and select the criteria which best suits the sustainable trim loss acceptable by the industry.

\section{CONCLUSIONS}


It has been noticed that the assessment of stock lengths, to cut different order sets for 1DCSP, has resulted in minimum trim loss. The stock length determined at every step is checked against the sustainable trim loss. At the end the model computes the total trim loss which has been observed to be very minimal. Three criteria are discussed which can be used to lower the number of stock length assessed for the feasibility of the supplier and also which supports acceptable sustainable trim loss for the industry. This model can help industries to choose the appropriate level of stock to minimize the total costs and manage warehousing.

\section{REFERENCES}

1. Arbib C., Marinelli F., "Integrating process optimization and inventory planning in cutting-stock with skiving option: An optimization model and its application, ” European Journal of Operational Research, vol. 163(3),pp.617-730, 2005.

2. Belov G., Scheithauer G., "A cutting plane algorithm for the one-dimensional cutting stock problem with multiple stock lengths, " European Journal of Operational Research, vol. 141(2), 274-294, 2002.

3. Dikili A., Takinaci A., Pek N., “A new heuristic approach to one-dimensional stock-cutting problems with multiple stock lengths in ship production," Ocean Engineering, vol. 35(7), 637-645, 2008.

4. Erjavec J., Gradisar M.,Trkman P., "Assessment of stock size to minimize cutting stock production costs, ” International Journal of Production Economics, vol. (135)1, 170-176, 2012.

5. Gilmore P.C., Gomory R.E, “A Linear Programming Approach to the Cutting-Stock Problem,” Operation Research, vol. 9(6), 849-859, 1961.

6. Golfeto R.R., Moretti A.C., Neto L.L de Salles, “A genetic symbiotic algorithm applied to the cutting stock problem with multiple objectives, "Advanced Modeling and Optimization, vol. 11, 473-501, 2009.

7. Gradisar M., Trkman P., Erjavec J., “Cutting as a Continous Business Process, ” Economic and Business Review, vol 11(4), 285-300, 2009

8. Powar, P. L., et al. "One-Dimensional Cutting Stock Problem (1D-CSP) with First Order Sustainable Trim: A Practical Approach." International Journal of Computer Science Engineering and Information Technology Research (IJCSEITR) 3.3 (2013): 227-240.

9. Gupta, Rashmi, and Ratnesh Rajan Saxena. "Set packing problem with linear fractional objective function." International Journal of Mathematics and Computer Applications Research (IJMCAR) 4.1 (2014): 9-18.

10. Agrawal, Abhishek., Rajesh Kumar Soni, and N. E. E. L. E. S. H. Dwivedi. "Development of integrated CNC-RP system through CAD/CAM environment." International Journal of Mechanical and Production Engineering Research and Development (IJMPERD) 4.6 (2014): 29-38.

11. Sharma, Avnl, And K. Venkata Subbaiah. "Multi-Objective Optimization Of Cutting Parameters In Hard Turning Process Using Genetic Algorithm (Ga) \& Artificial Neural Network (Ann)." International Journal of Mechanical and Production Engineering Research and Development (IJMPERD) 4.6 (2014):13-18

12. Matarneh, Mohammad Essa. "Improvement of abrasive and edge cutting machining efficiency through theoretical analysis of physical conditions." International Journal of Mechanical and Production Engineering Research and Development (IJMPERD) 8.2 (2018): 249-262.

13. Joshi, Jyoshna, and Onkar Sonare. "Optimisation of Wire EDM Process Parameters on D3 Tool Steel using Principal Component Analysis." International Journal of Mechanical and Production Engineering Research and Development (IJMPERD) 7.2 (2017): 31-40. 
